\title{
Peripheral Nerve Abscess in Leprosy Report of Three Cases Encountered in Dimorphous and Lepromatous Leprosy*
}

\author{
CARL D. ENNA and PAUL W. BRAND \\ USPHS Hospital, Carville, Louisiana, U.S.A.
}

\begin{abstract}
A review of the literature pertaining to peripheral nerve abscess in leprosy is presented. Relevant features indicate that it is rare, occurring most commonly in males and almost exclusively in patients with tuberculoid leprosy; also that it may involve either the peripheral trunk or cutaneous branches, which involvement is correlated with definite clinical patterns. Three cases recently encountered at Carville are reported. They are of interest because they occurred in lepromatous and dimorphous cases of leprosy which were complicated by acute ENL reaction. Also, each abscess originated within the trunk of the ulnar nerve and had different features of interest. The principles of surgical management of caseation and abscess are discussed. In view of the infrequent occurrence of this condition fuller reporting of such cases is advocated, for this would aid in providing a better understanding of the entity.
\end{abstract}

There are 1 elatively few articles on peripheral nerve abscess in the medical literature, and these are limited to cases due to leprosy. Certain relevant features are emphasized: the incidence is considered to be rare, and it is noted to occur almost exclusively among males who have tuberculoid leprosy. Either the peripheral nerve trunk or the cutaneous branches may be affected. The pathology is variable, with the diagnosis of an abscess established on the basis of microscopic findings, or gross evidence of caseation, and definite cavitation with liquefied purulent exudate. Reports have emanated from India, Africa, Japan, and South America. Wade (1955) stated that peripheral nerve abscess has not been observed in the Philippines. Also, no cases have been reported from Hawaii or the National Leprosarium at Carville.

Notable of earlier reported case-histories is that they are brief, contain inadequate information, and there is a lack of uniformity of data pertinent to the subject. Though the greatest number of cases are encountered in men, one case is reported by Priestman (1967) in an 11-year-old girl with reacting tuberculoid leprosy, and Saikawa (1950) described one case

*Received for publication January, 1970. of multiple abscesses involving a tuberculoid macular case in an old woman. Only one case is reported in a patient with dimorphous leprosy (Sehgal et al., 1967).

Also, the report of nerve abscess in lepromatous leprosy is only occasional. Thus, Job and Bhaktaviziam (1967) report the case of an abscess involving a subcutaneous nerve, the diagnosis of which was established histologically, and Sato (1956) reports 3 cases of abscesses in lepromatous leprosy, one of which involved the ulnar nerve trunk. Differentiation is made between the clinical manifestations resulting from involvement of the nerve trunk and the cutaneous branches. It was pointed out by Lowe (1934) that trunk involvement was common in Dichpali in contrast to involvement of cutaneous nerves in patients in Calcutta, and that there was a different pattern of clinical manifestations corresponding to each.

The nerve trunks reported involved are: (a) the ulnar nerve at the elbow, this being the most frequently cited, (b) the common peroneal, (c) the posterior tibial, (d) the external popliteal, and (e) one case involving the sciatic nerve (Mukherjee and Ghosh, 1956). Cutaneous nerves reported having abscesses include (a) the great 
auricular, (b) the cutaneous nerves of the arm, (c) the cutaneous nerve of the forearm, (d) the cutaneous nerve of the median in the arm, (e) the cutaneous branch of the ulnar on the dorsum of the hand, (f) the radial nerve branch to the dorsum of the hand, (g) the posterior cutaneous nerve of the leg, (h) the superficial peroneal, (i) the saphenous, and (j) the sural nerve. Although abscesses have been encountered in cutaneous branches of the median (Gupta, 1962) and radial (Wheate, 1964) nerves, it could not be determined from the literature that the trunk of either nerve has been involved.

Detailed descriptions of both the gross and the microscopic pathology are generally wanting. However, the findings reported in the various papers cited are comparable. The diagnosis of an abscess is established from both its histopathological and gross pathological features. Gross findings vary from caseous tissue to liquefied or inspissated, yellow, purulent exudate. The disintegrated tissue may appear as a dry grumous or cheesy material. Caseous nodularity of nerves in tuberculoid leprosy is also described (de Souza Campos, 1936); however, they are not always identified as abscesses. In other instances, the disintegrated tissues are autolysed, and there is a purulent exudate. These findings are reported in both the tuberculoid and lepromatous types of leprosy. The Mycobacterium le prae bacilli are demonstrable in only approximately $50 \%$ of cases (Lowe, 19:34), which have been reported to be dominantly of the tuberculoid type. The size of the abscess varies. The majority are observed clinically as a localized swelling. On the other hand, the actual abscess associated with a swollen nerve may be so small that the diagnosis is established only incidentally during surgery or by the pathologist when examining the surgical specimen (Casile et al., 1954). Localized swelling does not always indicate a true abscess, as we have observed repeatedly upon surgical exploration. Fusiform neural enlargement is often due to leprous inflammation. There may be localized cellular necrosis within the swelling, but the neural framework is intact, and the affected focus remains adherent. Minute abscesses are en- countered incidentally. On the other hand, giant-sized abscesses are occasionally seen (Gupta, 1962; Mukherjee and Ghosh, 1956) which suggest, and require differentiation from, a tumour.

Reports of nerve abscess in lepromatous leprosy are few, and in only one instance is the nerve trunk reported to have been involved as compared to cutaneous nerve involvement (Sato, 1956). Interest in the subject of nerve abscess and pure neuritic lesions in lepromatous leprosy has been indicated by Wade (1955). Whereas the question whether nerve abscess occurs in lepromatous leprosy has now been answered (Sato, 1956; Job and Bhaktaviziam, 1967), a related question submitted was "Do they occur without coincident skin lesions?" This question is raised because nerve abscesses have developed in patients with lepromatous leprosy who are in acute reaction. It appears pertinent to this inquiry that the site of the abscess should be indicated in relation to the lesions of erythema nodosum leprosum (ENL), whether it be cutaneous or truncal in origin.

In the past few years, nerve abscesses have been encountered in 3) cases of lepromatous and dimorphous leprosy at Carville. In view of the rarity of reports on peripheral nerve abscesses observed in types of leprosy other than the tuberculoid, and because each case presents different features of interest, it is felt that the report of these :3 cases is warranted.

\section{CASE REPORTS}

No. 2549, male, date of birth 16-12-25; Filipino, with dimorphous leprosy (BL). Trouble intermittently with ENL, reactions and was receiving steroid therapy. Clinically, there was persistent pain and tenderness accompanying a localized swelling of the ulnar nerve at a site proximal to the medial aspect of the elbow. On 11-7-63 a neurolysis and transposition of the ulnar nerve was done. Three small areas of caseation necrosis were associated with a fusiform enlarged nerve trunk. The abscesses were situated beneath the epineurium, which had to be incised to evacuate them. The material 
was grossly caseous with numerous acid-fast bacilli. The pathologist's report of tissue submitted was as follows: "The nerve branches and bundles are greatly scarred with distorted architecture. However, all showed a few bacilli which stain well". Diagnosis was leprous neuritis, active (report signed G. L. Fite).

\section{Comment}

This case of dimorphous leprosy (BL) represents an incidence in which multiple small areas of caseation containing acid-fast bacilli were associated with a fusiform enlarged ulnar nerve trunk showing scarring and a distorted architecture.

No. 2543, female, date of birth 11-8-39, Filipino, with lepromatous leprosy (LL). There had been a recent ENL reaction which responded to prednisone but had recurred with ulnar nerve pain. "Hydeltrasol" was injected around and into the nerve without relief of pain. Two previous left ulnar neurolyses had been performed, on 8-5-63 and 31-10-63 respectively, by different surgeons. Because of persistent localized pain and swelling which did not respond to non-srical measures, a third neurolysis was done on 24-4-64. An ulnar nerve abscess was suspected pre-operatively. At operation a greenish-coloured neural bundle was noted. It was incised and a soft exudate extruded. Tissue was submitted to pathology. The report stated: "Skin fragments possessed a few scattered lepromatous foci of small to moderate numbers of bacilli. In an area of the subcutaneous tissue there is a foreign body granulomatous type lesion showing some partly acid-fast; it suggests the residue of inoculated material. The perineural scar tissue shows much more of the foreign-body reaction, many giant cells containing weakly acid-fast ovoid bodies suggesting colloidal particles. Another area shows many brilliant orange granules, also with some foreign-body change. The impression of previous infection or surgical intervention with residue is very strong. The nerve bundle with abscess is more of a foreign-body change, including all and more of those described. 1)iagnosis: Foreign-body reaction about ulnar nerve, left. Probably residual from prior injection of material in oily suspension".

\section{Comment}

This case of lepromatous leprosy (LL) represents a foreign-body abscess in an ulnar nerve possessing leprous disease and complicated with scarring from 2 previous procedures. It cannot be determined if it is superimposed upon a pre-existing leprous abscess, even though acidfast bacilli were present. It is presumed, therefore, in view of the dominant foreign-body reaction, that the abscess was probably iatrogenic in origin.

No. 2757, male, date of birth 12-33-21, Mexican, with lepromatous leprosy. This patient developed an ENL reaction which responded satisfactorily to prednisone except for the persistence of a painful and tender localized swelling involving the right ulnar nerve, proximal to the elbow. On 6-6-69) an abscess of the ulnar nerve trunk was evacuated surgically and the nerve was lysed and transposed. Postoperatively there was an exacerbation of the ENL reaction, although the symptoms and signs referable to the ulnar nerve had completely subsided. Because of the exacerbation of ENL, in spite of further prednisone, therapy was supplemented with thalidomide, following which the reaction subsided. Smears obtained from the viscid exudate of the abscess revealed numerous acid-fast bacilli (AFB). The pathology report was as follows: "(a) Subcutaneous tissue, right arm, revealed fibro-fatty tissue with moderate size vessels and prominent small intact nerves. Stains for AFB reveal rare fragments within certain small nerves. Bacterial index $(B I)=0-1+$, morphological index $(M I)=0$. (b) Epineurium right ulnar nerve reveals dense fibrous tissue with scattered chronic inflammatory cells, predominantly lymphocytes. In the larger piece of tissue, old foamy histiocytes are present. Stains for AFB reveal a focus of rare, beaded bacilli within the larger focus and on occasion in smaller pieces of the fibrous tissue. $\mathrm{BI}=0-2+, \mathrm{MI}=0$. (c) Fascicules, right 

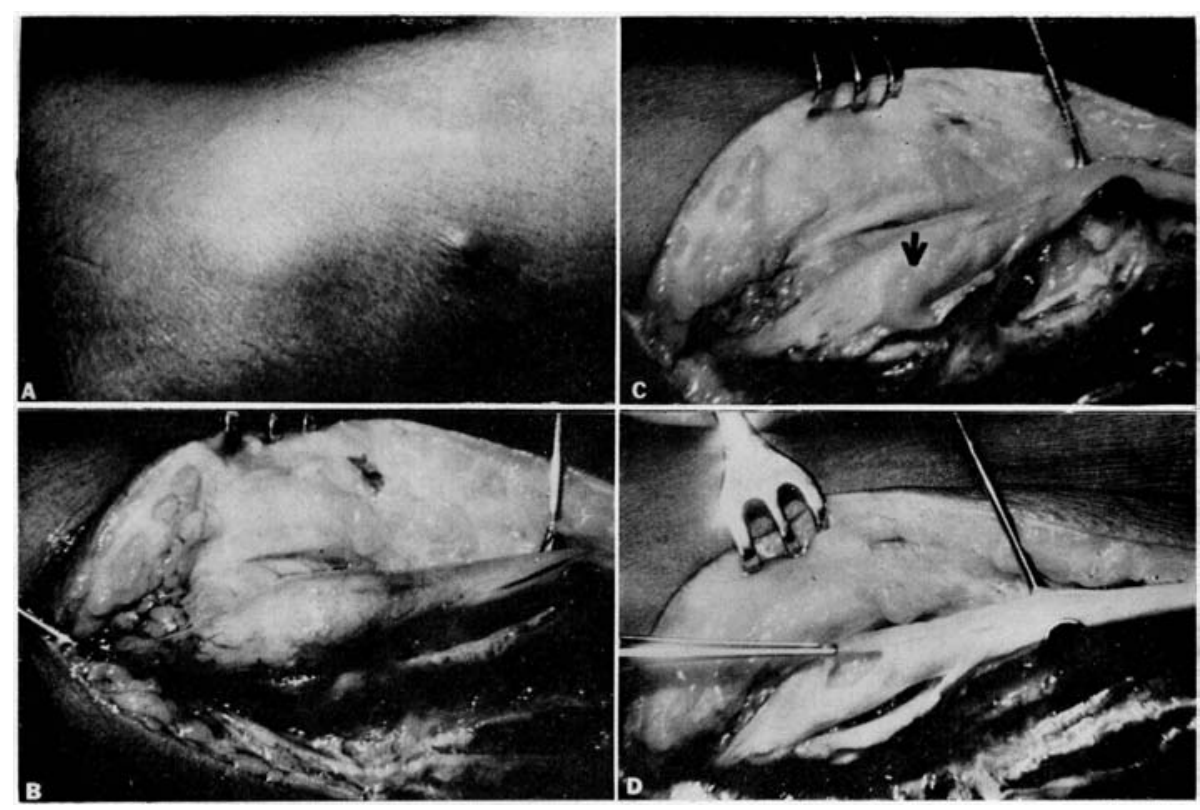

FIG. 1

Leprous alsscess of ulnar nerve proximal to epicondylian groove. A, Localized swelling medial aspect forcarm near the elbow; B, Fusiform swelling of the nerve; C, Arrow pointing to a purulent exuclate escaping from cavity; D, Cavity following evacuation.

ulnar nerve, reveals cross-section of a very small nerve showing a definite lepromatous infiltrate with focal fibrosis. A moderate amount of oedema separates remaining nerve axons. Stains for AFB reveal generally moderate numbers of beaded bacilli with a rare solid noted only in one section. (d) Medial intramuscular septum, right arm, reveals fibro-fatty tissue; in addition, these reveal small nerves, possessing lepromatous infiltrate and slight prominence of the perineurium. Stains for AFB reveal moderate number of beaded bacilli within the nerves. A focus of what appears to be made on $\mathrm{H} \& \mathrm{E}$ section contains also moderate numbers of beaded bacilli. (c) and (d) $\mathrm{BI}=\mathbf{4}+, \mathrm{MI}=\mathbf{0}$. Diagnosis: Tissue right arm, lepromatous leprosy, active, with moderately severe involvement of nerves".

\section{Comments}

This is a case of lepromatous leprosy in which a peripheral nerve abscess is encountered within the ulnar nerve trunk at a site proximal to the elbow (Fig. 1). Although its development is associated with an episode of ENL reaction, it was centrally located within the nerve, and were was no apparent contiguous involvement to skin lesions. Thus, this peripheral nerve abscess encountered in a case of lepromatous leprosy has its origin within the nerve trunk and is not related to coincident ENL skin lesions.

\section{DISCUSSION}

Peripheral nerve abscess appears to be unique to leprosy. Although the majority of reported cases have been in patients with tuberculoid leprosy, it is also encountered in dimorphous and lepromatous cases. It occurs in both sexes, but with greater frequency in the male. An abscess may involve either the peripheral nerve trunk or the cutaneous branches, and the lesion may be independent of, or contiguous with, skin lesions of acute ENL reaction.

A review of published reports reveals a lack of uniformity of basic information on the 


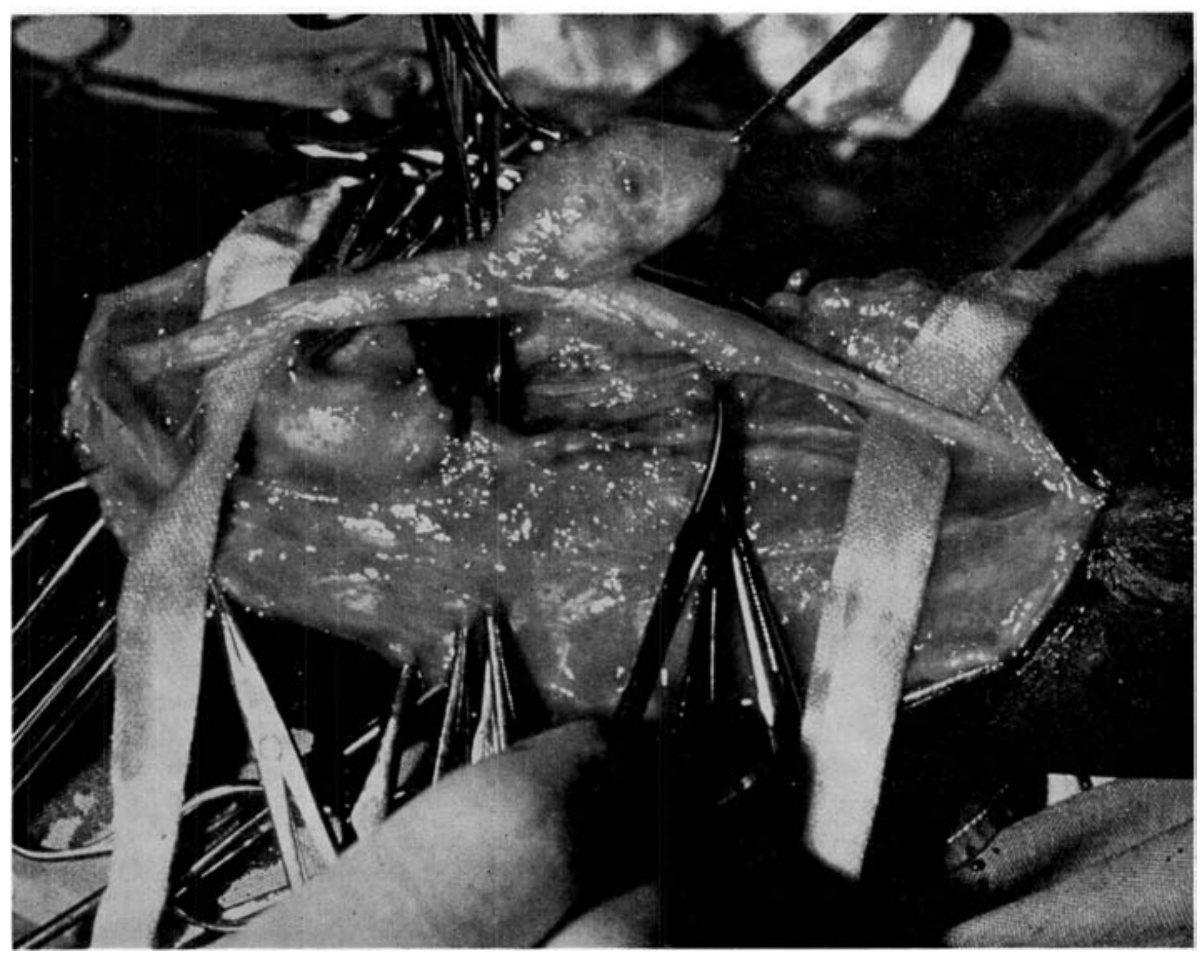

Fig. 2

A saccular leprous abscess communicating with the tibial nerve within the popliteal space.

subject matter in many instances. A better understanding of the subject could be attained if the adequate biomedical data were provided in each case. It should include sex, age, type of leprosy, the basis for establishing the diagnosis of abscess, the site of neural involvement, that is whether trunk or cutaneous, the presence or absence of acute reaction, and the relation of the abscess to ENL lesions of the skin if such exists. It would also be of value to know the functional status of these nerves during the period that the abscess was present and also following surgical treatment.

The criteria for establishing the diagnosis of peripheral nerve abscess may be controversial. The terms "caseation" and "cold abscess" are common to both tuberculosis and leprosy. In tuberculosis, the classic sequence of focal necrosis, followed by caseation, and subsequently a cold abscess is not unfamiliar. A similar progression of events is seen in peripheral neuritis of leprosy. Caseation literally means "of the nature of cheese". Histologically it consists of a necrosis of tissue with complete loss of structure. A finding which resembles but is not true caseation is the presence of an area of cellular necrosis within which there is a continuity of collagen framework. The necrotic substance is adherent and cannot be removed by scraping with a blunt instrument, as caseous material can be. In this instance the fasciculus undergoes cellular necrosis without caseation. The process may be focal or continuous and may be located between fasciculi which are intact and functional. It may progress to such complete destruction of all tissue elements that the material becomes caseous, whereupon it can be easily removed by simply "spooning it out" with a dull instrument. Following caseation, a true abscess may occur. A granulomatous 
exudate producing a cold abscess develops slowly, whereas an abscess complicated by secondary infection is manifested more acutely. When an abscess forms within the nerve trunk, it may either burst through the perineurium but remain contained within the epineurium to produce a localized fusiform swelling, or it may migrate, extending by a narrow tract that leads to a saccular swelling within adjacent soft tissues (Fig. 2). In our practice we confine the surgical diagnosis of abscess to gross collections of caseous material, and semi-fluid or fluid purulent exudate. When an abscess co-exists with adjacent caseous material, we advise evacuation of the abscess together with the caseous nerve bundle that has given rise to it. This permits of primary closure and healing of the wound. If only the purulent exudate is evacuated, then either the abscess may recur or a sinus tract communicating with the focus of caseous residue will develop. On the other hand, caseation alone does not necessarily require surgical intervention except when it results in enlargement of the nerve that increases the intraneural tension whereby it produces pain or progressive paralysis.

\section{REFERENCES}

BROWNE, S. G. (1957). Leprous nerve abscess. Report of 2 cases. Lepr. Rev. 28, 20.

BRowne, s. G. (1965). Nerve abscesses in African leprosy. Lepr. Rev. 36, 55.

DE souza Campos, N. (1936). Tuméfaction caséeuse des nerfs au cours de la lèpre. Etude des nevrites nodulaires caséifiées de structure tuberculoïde. Int. J. Lepr. 4, 1.

DE Souza CAMpos, N. and Ribeiro, E. B. (1941). Nevrite e caseose de nervo na lepra tuberculoide. Ann. Paulist. Med. Cirurg. 6, 527.
CASIle, M., SACCharin, H. and Destombes, P. (1954). An anatomical and clinical study of leprous tuberculoid polyneuritis of the tibial nerves, with caseation and arteritis. Int. J. Lepr. 22, 123.

GARzon, R. and PITT, L. A. (1943). Neuritis leprosa tuberculoide a forma de abscesos caseos multiple. Revta. Argent. Dermatosif. 27, 247.

GRIECO, v. (1936). Estudo clinico e histologico de un caso de nevrite hanseniana tuberculoide con caseificacão e ulceracão (absceso de nervo). Revta. Bras. Leprol. 4, 151.

GUPTA, R. L. (1962). Giant nerve abscess in leprosy. Case report. Lepr. India 34, 205.

јов, с. к. and внактаviziam, с. (1967). Nerve abscess in lepromatous leprosy. Report of a patient. Lepr. Rev. 38, 243.

LOWE, J. (1934). A further note on nerve abscess in leprosy. Int. J. Lepr. 2, 301.

MUKheRJEe, N. and GHOSh, s. A. (1956). A case of leprosy mistaken for nerve tumour. J. Indian Med. Ass. 27, 291.

Priestman, F. G. (1967). Nerve abscess in Northern Nigeria. Lepr. Rev. 38, 35.

SAIKAWA, K. (1950). A rare case of multiple nerve abscess in an old woman. La Lepro 19, 4. (In Japanese -English abstract p.1.)

SAIKAWA, K. (1951). The histopathological studies of the peripheral nerve in the various clinical phases of leprosy. La Lepro 20, 99. (In Japanese-English abstract p. 99.)

sato, s. (1956). Nerve abscess in lepromatous leprosy. Report of a case, with a review of reports of nerve abscess in Japan. Int. J. Lepr. 24, 408.

schuJMan, s. (1935). Coexistencia de abceso nervioso y lepra tuberculoide. Rev. Leprologia de Sao Paulo $2,277$.

SEHGAL, v. N. (1966). Nerve abscesses in leprosy in Northern India. Lepr. Rev. 37, 109.

SEHGAL, v. N., TULI, s. M. and DUBE, B. (1967). Leprotic nerve abcesses in Northern India. Int. J. Lepr. 35,60 .

TILAK, C. T. (1966). Anterior transposition of ulnar nerve in leprosy. Lepr. Rev. 37, 41.

WADE, H. H. (1955). Nerve abscesses and pure neuritic lesions in lepromatous leprosy. An editorial. Int. $J$. Lepr. 23, 69.

wheate, H. W. (1964). Two unusual cases of nerve abscess. Lepr. Rev. 35, 86. 